\title{
Successful repair of coronary artery-pulmonary artery fistula with coronary artery disease and atrial septal defect in an adult
}

Živojin S. Jonjev, MD, PhD, Aleksandar Milosavljević, MD, Aleksandar Redžek, MD, and

Vladimir Č. Torbica, MD, Novi Sad, Serbia and Montenegro

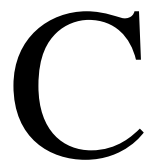

oronary artery fistula is a very uncommon vascular communication between coronary arteries and other cardiac structures (chambers or great vessels). However, there have been several reports since 1865 with different variations in anatomy, level of communication, and clinical course. ${ }^{1}$ We report an adult case of coronary arteriovenous fistula arising from the left anterior descending artery (LAD) and draining anomalously into the main pulmonary artery (PA) combined with coronary artery disease (CAD) and atrial septal defect (ASD).

\section{Clinical Summary}

A 72-year-old man had chest pain and easy fatigability that progressively worsened 6 months before admission. The patient's medical history was positive for myocardial infarction, chronic renal insufficiency, uncontrolled arterial hypertension, and hyperlipoproteinemia type IIa. Physical examination and chest roentgenography demonstrated increased size of the heart. Electrocardiography confirmed old myocardial infarction of the posterior wall of the left ventricle, right bundle branch block, and myocardial hypertrophy, without signs of ischemia at rest. Cardiac catheterization studies showed the presence of a CAD and ASD, with a left-to-right shunt of $10 \%$. Coronary angiography revealed the dominance of the circumflex coronary artery, with a significant $90 \%$ stenosis of the first and second obtuse marginal arteries, $90 \%$ stenosis of the proximal segment of the LAD, and minor right coronary artery. A grossly dilated, tortuous coronary artery fistula was found arising from the very proximal segment of the LAD proximal to the LAD stenosis and entering the proximal PA (Figure 1). The left ventricle had akinesia of the posterior wall, hypokinesia of the anterior wall, and significantly lower ejection fraction (ie, 30\%).

\footnotetext{
From the University in Novi Sad, Institute of Cardiovascular Diseases, University Clinic of Cardiovascular Surgery, Novi Sad, Serbia and Montenegro.

Received for publication Jan 8, 2005; accepted for publication Feb 8, 2005

Address for reprints: Živojin S. Jonjev, MD, PhD, University of Novi Sad, School of Medicine, Institute of Cardiovascular Diseases, University Clinic of Cardiovascular Surgery, Institutski put 4, 21204 Sremska Kamenica, Serbia and Montenegro (E-mail: jonjevz@lycos.com).

J Thorac Cardiovasc Surg 2005;130:890-1

$0022-5223 / \$ 30.00$

Copyright (C) 2005 by The American Association for Thoracic Surgery

doi:10.1016/j.jtcvs.2005.02.021
}

On February 5, 2004, the patient underwent surgical intervention. Intraoperative transesopha-

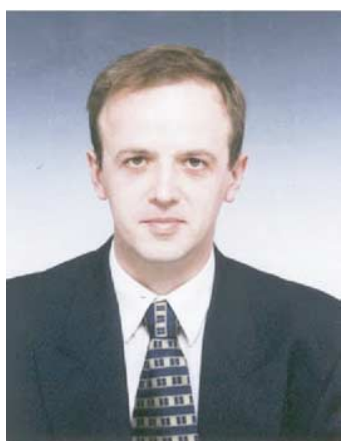

Dr Jonjev geal echocardiography (TEE) was used to evaluate the structure and function of the heart, the location of the ASD, the LAD-PA fistula, and the results of repair. TEE was performed with the General Electric Vivid 7-PRO system and Medical Systems-GE TEE probe (model 6T-5.0 MHz) before and after cardiopulmonary bypass (Figure 2). After heart exposure, the large LAD-PA fistula was visible at the surface of the base of the heart. Using complete cardiopulmonary bypass, we induced cardiac arrest with cold crystalloid cardioplegia. The LAD-PA fistula was closed proximally and distally with separate direct monofilament 5-0 sutures, and myocardial revascularization was successfully achieved with triple coronary artery bypass grafting. Finally, the ASD was also closed with direct monofilament 4-0 sutures. The postoperative course of the patient was uneventful, and his condition was stable 11 months after the operation.

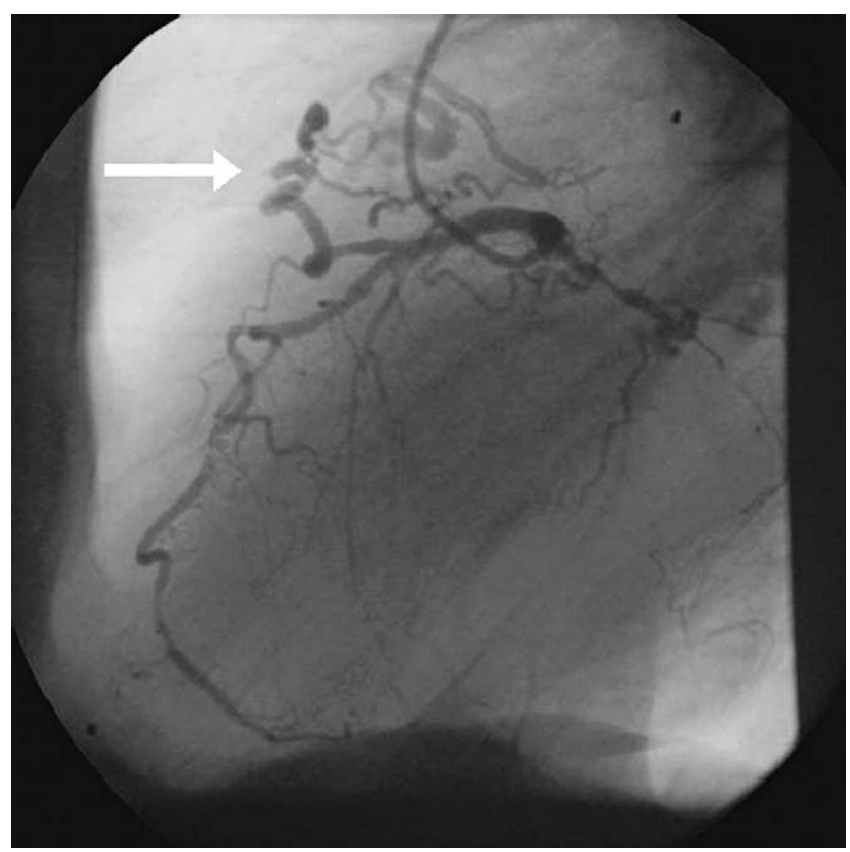

Figure 1. Preoperative LAD injection showing a large fistula originating from the proximal segment of the LAD. Drainage was to the proximal segment of the PA. The arrow indicates the LAD-PA fistula. 


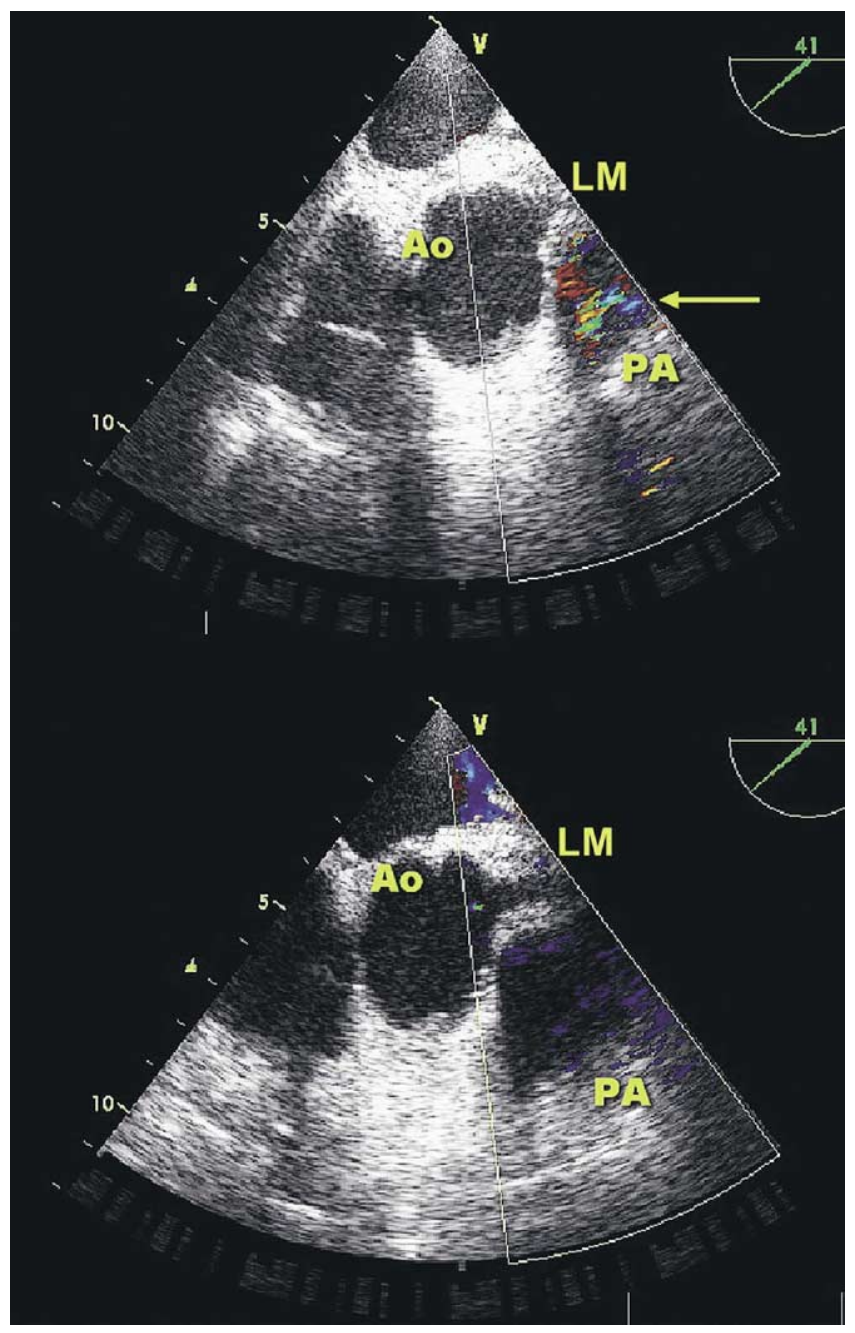

Figure 2. Intraoperative TEE before and after closure of the LAD-PA fistula. The color Doppler image demonstrates the existence of flow between the LAD and PA before closure (upper view). The postoperative image shows normal clinical findings (lower view). Ao, Aorta; LM, left main trunk.

\section{Discussion}

Coronary arteriovenous fistula is an uncommon cardiac malformation routinely found on cardiac angiograms. In the present case the anomaly was found as an LAD-PA fistula combined with a CAD and an ASD. Not many reports are available in the literature on coronary artery-PA fistulas. However, the inci- dence of this anomaly is reported to be less than $1 \%$ of all congenital heart defects. ${ }^{2}$

In embryonic life, coronary arteries communicate with ventricular chambers, great vessels, or both, through the branches recognized as sinusoids. Later on, the sinusoids transform into a normally calibrated capillary network. There is speculation that unclosed sinusoids or attachment of the main coronary artery to the pulmonary trunk could be a potential source for major congenital coronary fistulas. ${ }^{3}$ If diagnosed in an adult, coronary artery fistula could be a consequence of inflammation, atherosclerosis, collagen vascular disease, or even trauma. ${ }^{4}$ In the present case the clinical history, size, and location of the fistula indicate a congenital origin with CAD.

The clinical findings associated with coronary fistulas are extremely variable. The fistula could be highly symptomatic, leading to congestive heart failure, or totally asymptomatic, depending on the coronary artery involved and the size of the fistula. In our case unstable angina was a dominant clinical finding, most likely as a consequence of CAD and LAD-PA fistula together.

Worsening angina and a possibility for the previously cited complications directed us to perform surgical treatment of the fistula. Precise selective coronary angiography is essential to locate arteriovenous fistula and to avoid myocardial ischemia, infarction, or both, after ligation of a coronary artery fistula. However, we highly recommend intraoperative TEE not only for intraoperative diagnosis but also for postoperative evaluation of the surgical results. This strategy might be helpful to avoid the residuals or recurrent fistulas that have been reported in the literature. ${ }^{4}$

In conclusion, we report a rare case of a successful repair of LAD-PA fistula combined with triple coronary artery bypass grafting and ASD closure in an adult. The patient survived the operation without postoperative complications and has remained well and without recurrence 11 months after the operation.

We thank Saša Potić for assistance in preparing this manuscript.

\section{References}

1. Akashi H, Tayama E, Tayama K, Fukunaga S, Tobinaga S, Sakashita H, et al. Rupture of an aneurysm resulting from a coronary artery fistula: a case report. Circ J. 2003;67:551-3.

2. Castedo E, Oteo JF, Burgos R, Ugarte M, Cristobal C, Tebar E, Ugarte J. Coronary artery fistula as a bypass of a left anterior descending coronary artery stenosis. Ann Thorac Surg. 1997;64:1813-4.

3. Hirooka K, Hanatani A, Nakatani S, Yasumura Y, Bando K, Miyatake $\mathrm{K}$, et al. Huge saccular aneurysm in a coronary-pulmonary fistula fed by the left and right coronary arteries. Circ J. 2002;66:525-7.

4. Abe T, Kamata K, Nakanishi K, Morishita K, Komatsu S. Successful repair of coronary artery-coronary sinus fistula with aneurysm in an adult. Ann Thorac Surg. 1996;61:1520-3. 